\title{
A utilização da inteligência competitiva na seleção de mercados para exportação: Uma análise comparativa de quatro métodos
}

\author{
Moema Pereira Nunes e Laura de Souza Lequain ${ }^{1}$
}

Pontifícia Universidade Católica do Rio Grande do Sul - PUC/RS, Porto Alegre, RS, Brasil

\section{DETALHES DO ARTIGO}

\section{Histórico do artigo:}

Recebido em 21 de dezembro de 2015

Aceito em 08 de novembro de 2016

Disponível online em 31 de dezembro de 2016

Sistema de Revisão "Double Blind Review"

Editor científico

Ilan Avrichir

\section{Palavras-chaves:}

Inteligência Competitiva

Exportação

Seleção de Mercado

\begin{abstract}
RESUMO
A inserção no mercado internacional através das exportações é uma importante etapa no crescimento de uma organização, mas, sobretudo para pequenas e médias empresas, é um grande desafio para os tomadores de decisão. Este trabalho verifica como a Inteligência Competitiva auxilia nesta escolha através de quatro métodos de seleção de mercados para exportação. A partir da análise de dados primários e secundários, quatro métodos foram investigados. Foram identificadas quatro dimensões estratégicas para o desenvolvimento da seleção de mercado para exportação: distância psíquica, análise setorial, etapas de seleção e indicadores. Foram identificadas as semelhanças e as diferenças entre estes métodos a partir da análise destas dimensões. Dentre os resultados obtidos, é verificada a grande diversidade de indicadores utilizados, a atenção fornecida à distância psíquica e a importância de uma análise setorial.
\end{abstract}

(c) 2016 Internext | ESPM. Todos os direitos reservados!

\section{Introdução}

A globalização estabeleceu um novo conceito de interação e fluxos globais nos diversos setores da sociedade e da economia. A expansão das atividades de uma empresa para fora das fronteiras de seu país de origem apresenta-se, muitas vezes, como uma importante etapa na busca pela expansão de uma organização. A internacionalização de empresas permite 0 acesso a novos mercados gerando vantagens significativas como o aumento do ciclo de vida do produto e das receitas operacionais, a prática de preços mais rentáveis e a diversificação dos mercados com uma consequente diluição dos riscos (Kovacs, Moraes, \& de Oliveira, 2008). No entanto, à medida que a globalização permite um acesso mais fácil aos novos mercados internacionais, ela também cria um acirrado ambiente de concorrência, que exige um crescimento contínuo da competitividade das empresas. Dessa forma, a inserção neste novo espaço negocial demanda um planejamento elaborado e cuidadoso, que esteja inserido dentro da estratégica mais ampla da organização.

Embora existam diversas teorias sobre o processo de internacionalização de empresa, a exportação é, na maior parte dos casos, e, sobretudo nos modelos de viés comportamental, vista como uma das primeiras etapas no gradual processo de penetração. Ela é muitas vezes utilizada com a finalidade de adquirir experiência e conhecimento no processo de internacionalização, conferindo à empresa uma maior cultura exportadora (Ferreira, Cavalcanti Neto, \& Gomes, 2014). Apesar de aparecer como o modo de entrada mais simples e que demanda menor controle por parte da empresa, a exportação deve ser uma ação estrategicamente planejada e pode exigir importantes mudanças na organização.

Para as empresas que almejam exportar seus produtos, um dos grandes desafios é a escolha do mercado importador. Um dos dilemas mais críticos

\footnotetext{
${ }^{1}$ Contato da autora: Email: lauralequain@falconi.com
} 
na análise de um novo mercado internacional é a escolha entre um nível de detalhamento mais alto e a consequente qualidade da análise versus os custos e o tempo envolvidos no processo decisório. Sobretudo as pequenas e médias empresas possuem pouca disponibilidade de recursos para fazer este trabalho e a posterior inserção no mercado internacional. Atualmente, existe também a crescente necessidade de tornar os processos decisórios mais rápidos, devido à velocidade com que o comercio internacional e os cenários se transformam (Teixeira \& Flores, 2014).

É fundamental que o processo de prospecção de novos mercados internacionais seja sustentado por um estudo sólido e eficaz, capaz de auxiliar os tomadores de decisão a realizarem a escolha mais adequada em um período de tempo restrito. A utilização da Inteligência Competitiva (IC) aparece, portanto, como um processo estratégico primordial para redução das incertezas e para a melhor compreensão das forças de natureza econômica, político-legal e cultural dos mercados internacionais. Segundo Fuld (2007), a IC permite uma ação antecipada frente à compreensão, menos do que perfeita, do cenário externo. A IC permite que sejam analisadas as informações do ambiente externo oriundas de diversas fontes e sejam compreendidas as formas de atuação neste mercado, embasando a definição da melhor estratégia para a empresa se estabelecer nele (Woida \& Valentim, 2013).

Uma das formas de emprego da IC são os métodos de seleção de mercado para exportação. A utilização da IC suporta os tomadores de decisões das empresas em diferentes finalidades (Barreto, 2012). A sua utilização na seleção de mercados para exportação representa uma destas oportunidades, auxiliando a reduzir os riscos de uma importante etapa do processo de internacionalização de uma empresa. Assim, este estudo tem como problema de pesquisa: Como a IC pode auxiliar o processo de seleção de novos mercados nas atividades de exportação?

Para responder a esta questão, a pesquisa traz como objetivo geral analisar a forma através da qual a IC tem auxiliado a seleção de novos mercados. Como objetivos específicos buscou-se identificar semelhanças entre os modelos de IC voltados a seleção de mercado para a exportação, bem como confrontar as diferenças dos métodos, de forma a revelar a capacidade de contribuição dos mesmos.

\section{Inteligência competitiva}

Segundo Sharp (2009), a IC é uma facilitadora do processo de formulação estratégica, compreendendo "as atividades de suporte à direção da organização com o objetivo de interpretar as informações a respeito de elementos do seu ambiente externo, de maneira a antecipar oportunidades e ameaças, por intermédio de processos analíticos" (Buzzerio \& Marcondes, 2014). Para Miller (2002) "a IC trata da análise das informações sobre o mercado e da geração de recomendações para os que decidem dentro das empresas".

Atualmente a IC é vista como um processo, no qual existe uma sequência lógica das atividades, com premissas, objetivos e expectativas prédeterminadas (Woida \& Valentim, 2013). Nesta visão, o ciclo de IC passa por cinco principais etapas, através das quais os dados são transformados em conhecimento: planejamento e direcionamento, coleta de informações, análise, comunicação e feedback (Calof \& Wright, 2008).

A primeira etapa consiste em compreender quais são o objetivo e as necessidades da utilização da IC e quais são os resultados esperados dela, de forma que seja definido o que é preciso monitorar. A segunda etapa, de coleta das informações, será determinante para assegurar a confiabilidade do resultado final e, em um momento anterior à coleta propriamente dita, deve-se definir os processos de coleta mais adequados, os modelos analíticos a serem utilizados e os papéis dos coletores. A etapa de análise das informações é considerada a que mais gera valor ao trabalho de IC, pois nela é criado o conhecimento estratégico voltado à ação (Buzzerio \& Marcondes, 2014; Bose, 2008). Nesta atividade, as informações obtidas na etapa anterior serão tratadas e interpretadas, obtendo significados a partir da identificação de padrões e tendência, de contextualizações e insights (Miller, 2002). A quarta etapa consiste na disseminação dos resultados, que devem ser apresentados não apenas como dados consolidados, mas sim com relações causais, hipóteses, visões e proposições para novos monitoramentos, pois estes são os reais produtos da IC. A última etapa consiste no feedback em relação ao produto de inteligência entregue e tem como objetivo avaliar a eficiência do sistema criado para atender às necessidades dos tomadores de decisão (Bose, 2008). 
Através destas etapas, as informações se transformam em conhecimento, que pode ser usado como suporte pela alta administração das organizações nas suas tomadas de decisão. Uma das áreas na qual a utilização da IC pode trazer ganhos substâncias na tomada de decisão é a da internacionalização de empresas, tema tratado a seguir.

\section{Internacionalização de empresas}

Os estudos sobre internacionalização através de exportações iniciaram com a análise das formas de identificar as oportunidades e os obstáculos à internacionalização das empresas em um mundo cada vez mais globalizado. Diante de uma gama de estudos sobre o assunto, duas principais vertentes se consolidaram e englobaram os diversos modelos desenvolvidos: a abordagem econômica, e a abordagem comportamental (Dal-Soto, Alves, \& Bulé, 2014).

A abordagem econômica de internacionalização de empresas é composta por algumas teorias principais que possuem como pilar o foco em decisões apoiadas em dados e informações concretas e a maximização dos retornos econômicos. Dentre os modelos que compõem esta abordagem destacam-se o Paradigma Eclético, a Teoria do Ciclo de Vida dos Produtos e a Teoria do Poder do Mercado (Dal-Soto et al., 2014). A abordagem comportamental tem como pilar os estudos da escola de Uppsala, desenvolvidos por Johansson e Vahlne. O pressuposto central desta escola é que a internacionalização ocorre de forma gradual e incremental, sendo resultado do crescimento da organização e da saturação do mercado interno atendido (Johanson \& Vahlne, 1977). A gradualidade de aprendizado é um foco importante da escola de Uppsala. O conceito de distância psíquica é preponderante no debate comportamental e engloba não somente a proximidade física existente entre os países, mas também as questões culturais, tais como língua e práticas empresariais, que geram maior identificação e segurança às empresas que estão neste processo inicial de internacionalização (Teixeira \& Flores, 2014). A atualização do modelo de Uppsala incorporou principalmente a Teoria das Redes, de Johanson e Mattson (1988), que soma à importância dos recursos que a firma possui, o relacionamento entre os envolvidos no processo, sejam eles internos, como as subsidiárias, sejam eles externos, a exemplo de fornecedores e empresas de propaganda. Incorporado dentro desta rede de negócios, consolida-se o papel do empreendedor, central na Teoria do Empreendedorismo Internacional, de Oviatt e McDougall (1994), e nos estudos e S. Andersson (2000).

Apesar das divergências entre a abordagem comportamental e a abordagem econômica, observa-se que a exportação possui um papel central nos estudos apresentados, sendo inserida em diferentes fases no processo de internacionalização. Um ponto crítico para que a exportação seja bemsucedida é a seleção do mercado.

\section{Seleção do mercado para exportação}

Carneiro e Dib (2008) dividem a decisão de internacionalização em cinco dimensões, nas quais a decisão pela escolha do mercado surge, normalmente, após uma análise inicial dos motivos para realizar a internacionalização, a definição sobre os produtos ou serviços que serão incorporados neste processo e a escolha de quando iniciá-lo. A última etapa seria a definição do modo de entrada no mercado selecionado, mas os autores ressaltam que a ordem não precisa ser necessariamente linear (Carneiro \& Dib, 2008; Dal-Soto et al., 2014).

A definição sobre "para onde exportar" é a questão básica analisada nos estudos referentes à seleção de mercado. A resposta mais racional e simplificada, sobretudo se analisados apenas os fatores macroeconômicos, seria a da escolha por mercados com um maior potencial consumidor e, portanto, mercados que se encontram em um mais alto estágio de desenvolvimento. No entanto, sobretudo a vertente comportamental, irá mostrar que, além dos obstáculos de inserção em um mercado composto de consumidores mais exigentes e uma concorrência em maior quantidade e mais agressiva, a inserção nos mercados mais desenvolvidos pode exigir um grau de maturidade mais alto da empresa (Viana \& Hortinha, 2009).

Apesar das diferentes posições encontradas na literatura acerca das estratégias de internacionalização, duas macros etapas fazem a unanimidade. A primeira consiste na avaliação dos potenciais mercados através de variáveis. Nesta etapa, as empresas podem escolher valer-se de variáveis puramente macroeconômicas, ou inserir variáveis referente às questões de caráter legal, 
político e características sociais e culturais. $\mathrm{Na}$ segunda etapa, as empresas analisam, para estes mercados previamente selecionados, os custos, benefícios e riscos de cada um dos mercados (Coelho Neto, 2013).

$\mathrm{Na}$ Escola de Uppsala, Johanson e Vahlne desdobraram o processo de seleção de mercado em quatro principais fases. A primeira consiste na identificação dos países através de indicadores principalmente macroeconômicos, tais como PIB, população e taxas de crescimento. Na segunda fase são analisados fatores mais subjetivos de cada país, que auxiliam na identificação da distância psíquica tais como a distância geográfica e o desenvolvimento econômico - e que permitem a exclusão de mercados já identificados como inviáveis. A terceira fase consiste em uma análise mais complexa dos dados relativos aos obstáculos e vantagens da inserção naquele mercado. A quarta fase é a seleção final, na qual se realiza uma análise comparativa entre os objetivos da empresa e os resultados previstos com a inserção no mercado definido (Coelho Neto, 2013).

Kontinen e Ojala (2010) reforçam a importância da proximidade psíquica e, diferentemente dos próprios autores Johanson e Vahlne, consideram que as opções de mercado para as primeiras exportações de um país são, necessariamente, para os países com uma maior proximidade física, linguísticas, cultural, entre outros.

Viana e Hortinha (2009) identificam duas formas distintas das empresas de selecionarem o mercado alvo: a escolha oportunista e a escolha sistematizada. A escolha oportunista utiliza o gap de performance através do qual é possível identificar a diferença entre os recursos que a empresa possui e os recursos necessários para realizar a inserção no novo mercado, sendo, portanto, selecionados os mercados com menor distância entre estes dois valores. A escolha sistematizada é normalmente utilizada por empresas que já possuem algum grau de internacionalização anterior e que passam, dessa forma, a investir em mercados com maior potencial de desenvolvimento ou maior retorno de capital (Coelho Neto, 2013; Viana \& Hortinha, 2009). Convergente a essa diferenciação entre escolha oportunista e escolha sistematizada, Hollensen (2011) identifica uma distinção entre a ação de seleção de mercados para empresas que já possuem uma atuação expressiva no exterior e a de empresas que estão iniciando este processo.

\section{Método de pesquisa}

Considerando o caráter exploratório da pesquisa, a primeira etapa deste estudo compreendeu a identificação dos métodos de seleção de mercados a serem analisados seguindo critérios de acessibilidade e conveniência. Os pesquisadores decidiram analisar dois métodos acadêmicos, cujo desenvolvimento e aplicação esteja vinculado a instituições de ensino e pesquisa, e dois métodos com caráter executivo, vinculados a órgãos públicos ou entidades de apoio à exportação. A escolha de métodos de diferentes abordagens foi feita de modo a permitir um maior aprofundamento na análise comparativa dos dados. Além disso, confrontar métodos acadêmicos e executivos permite uma compreensão distinta de como o tema é tratado nestas duas esferas. Os dados de três métodos foram obtidos através de levantamento bibliográfico e o quarto método através de uma entrevista não estruturada.

O primeiro método apresentado foi o desenvolvido pela Agência Brasileira de Promoção de Exportações e Investimentos (APEX). A Agência o aplica, através de sua área de Inteligência de Mercado, para a confecção de estudos que objetivam pontuar oportunidades de mercados importadores para os produtos e serviços de setores brasileiros. 0 segundo método analisado foi desenvolvido pelos pesquisadores da Michigan State University, S. Tamer Cavusgil, Tunga Kiyak e Sengun Yeniyurt, e aplica simultaneamente os métodos de clusterização (agrupamento) e o rankeamento (classificação) dos países. O terceiro método foi elaborado por Nick Papadopoulos, Hongbin Chen e D. R. Thomas, pesquisadores da Eric Sprott School of Business da Carleton University.

O quarto método foi obtido através de uma entrevista com um analista do Núcleo de Inteligência Comercial do Centro Internacional de Negócios do Rio Grande do Sul (CIN-RS), pertencente à Gerencia de Relações Internacionais e Comércio Exterior da Federação das Indústrias do Rio Grande do Sul. O CINRS oferece capacitações e estudos que procuram estimular o desenvolvimento das indústrias no estado, através da ampliação das oportunidades de comércio exterior. O roteiro de entrevista encontrase no Apêndice 1.

Na sequência foi realizada uma síntese dos quatros métodos, visando orientar a etapa de análise dos mesmos. De posse das mesmas sentiu-se a necessidade de qualificar a análise incluindo a 
perspectiva de especialistas sobre o tema com o objetivo de incluir nesta análise o conhecimento empírico que os mesmos possuem sobre o tema. A síntese de cada um dos métodos foi compartilhada com cada um dos entrevistados. Foi elaborado um roteiro de perguntas para as entrevistas semiestruturadas realizadas. O primeiro entrevistado é mestre em Administração, professor e consultor na área de comércio exterior, com mais de 25 anos de experiência na área de comércio internacional. 0 segundo entrevistado é doutor em Estudos Estratégicos, especialista em internacionalização de empresas, professor e economista da vinculado ao governo estadual. $O$ terceiro especialista entrevistado é professor, coordenador do Grupo Temático de Negociações Internacionais da Federação das Indústrias do Rio Grande do Sul, e consultor de empresas. Os entrevistados foram escolhidos seguindo critérios de conveniência e acessibilidade, e as entrevistas foram realizadas individualmente e de forma presencial.

Após a realização das entrevistas, as respostas foram analisadas e quatro dimensões foram identificadas as principais para a análise dos métodos, a saber: distância psíquica, análise setorial, etapas de seleção e indicadores. Os dados foram analisados de forma intuitiva através da busca da adoção da técnica de análise de conteúdo. As categorias foram identificadas a partir da comparação dos dados com a teoria e posteriormente aplicadas no processo de categorização dos dados, seguindo assim os procedimentos propostos pela abordagem (Prodanov \& de Freitas, 2013).

$\mathrm{Na}$ sequência os quatro métodos são caracterizados e, posteriormente, a análise comparativa dos mesmos é realizada a partir das quatro dimensões identificadas.

\section{Apresentação dos métodos de seleção de mercados para exportação}

A seguir são apresentados brevemente os quatro métodos de seleção de mercados para exportação.

\subsection{O método da APEX Brasil}

A APEX Brasil atua como mediadora entre empresas e instituições nacionais e estrangeiras, estimulando a participação do Brasil no comércio internacional (APEX, 2015). Um dos estudos realizados é o de identificação de potenciais mercados importadores para produtos e serviços de setores da indústria brasileira.

A primeira etapa do método consiste em selecionar os 60 maiores importadores mundiais do produto em análise. Visto que os trabalhos analisados se referem a produtos brasileiros, soma-se a esta lista inicial os países sul americanos que se encontram entre os 100 maiores importadores mundiais. Essa diferenciação é justificada pela proximidade geográfica, que permitiria uma maior facilidade logística, a mais provável existência de acordos comerciais e a uma menor distância psíquica. Dentro desta seleção inicial, os países são separados em "Alto destaque", "Alto", "Médio-alto", "Médio-baixo" e "Baixo".

Para estes países pré-selecionados, é calculado o crescimento médio anual das importações do produto durante os últimos cinco anos. Nesta triagem, os países são classificados como "Muito dinâmicos", "Dinâmicos", "Intermediário", "Baixo Dinamismo" e "Em decadência". Todos os países que possuem "Alto destaque" e/ou "Muito dinamismo" são selecionados, bem como aqueles que apresentam combinações intermediárias.

A segunda etapa consiste em verificar dados relativos a cinco grandes temas: "comércio", "concorrência", "cenário macroeconômico", "acessibilidade" e "setorial". Dentro do tema "comércio", são observados dados que visam identificar a relação comercial do Brasil com os países selecionados e a capacidade importadora destes países. Os indicadores do tema "concorrência" têm como objetivo analisar a concorrência dentro do mercado-alvo, seja pela própria produção local, seja por terceiros países. Dentro da análise do "cenário macroeconômico" são observadas informações relativas ao poder e ao dinamismo econômico dos países selecionados, objetivando identificar as oportunidades internas do mercado. O grupo denominado "acesso" visa estudar pontos relacionados à logística e questões tarifárias, que influenciam de forma determinante a entrada dos produtos no mercado-alvo. As variáveis inseridas dentro do grupo "setorial" buscam identificar dados mais precisos dos países pré-selecionados sobre o setor do produto. Neste grupo, as variáveis selecionadas mudam de acordo com o produto que é analisado. Para cada uma das variáveis sugeridas, devem ser identificadas a média e o desvio padrão, 
comparando-se os países. Com estas informações, torna-se possível classificar os países, para cada uma das variáveis, em quatro categorias, conforme apresentado na Tabela 1.

Tab. 1

Pontuação das Variáveis

\begin{tabular}{cl}
\hline Pontuação & \multicolumn{1}{c}{ Faixa de valor do indicador } \\
\hline-1 & Valor abaixo da média em um desvio padrão ou mais \\
1 & Valor abaixo da média em até um desvio padrão \\
3 & Valor acima da média em até um desvio padrão \\
5 & Valor acima da média em um desvio padrão ou mais \\
\hline
\end{tabular}

Fonte: Elaborado pelos autores a partir de APEX (2015).

A última etapa deste método consiste em calcular a média desta pontuação para cada um dos países. Dessa forma, os países que obtiverem como média final os valores três ou cinco são apontados como potenciais mercados importadores para o produto analisado.

6.2 O método de clusterização e rankeamento de países

O método elaborado pelos pesquisadores Cavusgil, Kiyak e Yeniyurt (2004) procura utilizar simultaneamente dois diferentes métodos na prospecção de novos mercados: o agrupamento (clusterização) e a classificação (rankeamento) de países. O primeiro implica em agrupar países que possuem similaridades nas dimensões comerciais, econômicas, políticas e culturais. O segundo consiste em ordenar os países de acordo com sua pontuação para dimensões pré-selecionadas e consideradas relevantes no mercado internacional.

$\mathrm{Na}$ etapa de clusterização, para realizar o agrupamento dos mercados é necessário selecionar variáveis de acordo com o tipo de produto que será exportado. Cavusgil et al. (2004) apresentam uma listagem de 29 de variáveis: 25 delas obtidas através de uma revisão da literatura e as outras quatro incluídas para medirem atributos mais modernos.

Cavusgil et al. (2004) procuraram abranger, através destas variáveis, cinco principais temas: infraestrutura, bem-estar econômico, padrão de vida, tamanho do mercado e dinamismo. A infraestrutura busca representar o nível de desenvolvimento do país e o bem-estar econômico representa a sua prosperidade. O padrão de vida é representado pelos autores por três variáveis que abrangem três temas diferentes - a expectativa de vida, o desemprego e a taxa de alfabetização. O tamanho do mercado visa identificar o tamanho do possível público consumidor do produto e o dinamismo o potencial futuro deste mercado. O método sugere que sejam selecionadas algumas variáveis desta listagem de acordo com o produto a ser exportado.

Após calculadas as variáveis para cada país, os mesmos são agrupados de acordo com as suas similaridades. Em seguida, estes grupos serão numerados em ordem de atratividade, atribuindo-se maior ou menor peso para os fatores. Neste primeiro momento, ter-se-á grupos de países ordenados de acordo com critérios definidos como mais importantes. Porém, ainda não é possível identificar um mercado alvo único, mas sim um grupo de mercados similares considerados mais atrativos. Cavusgil et al. (2004) sugerem que seja aplicada uma técnica de classificação, através da qual os países são ordenados de acordo com sua potencialidade.

Esta técnica de classificação é baseada no Índice Potencial de Mercado, um indicador calculado e publicado anualmente no GlobalEdge pela Michigan State University e que possui como pilar oito dimensões: tamanho do mercado, intensidade do mercado, taxa de crescimento do mercado, capacidade consumidora do mercado, infraestrutura comercial, receptividade do mercado, liberdade econômica e risco do mercado. Foram dados pesos a estes pilares, calculados através de diversas aplicações do método Delphi entre estudiosos e profissionais de negócios internacionais. Foi aplicado um modelo de compensação linear e chegou-se a uma classificação para os 89 países analisados.

Combinando-se o método de agrupamento e de classificação, tem-se a identificação do mercado-alvo. O método sugere que seja realizada uma análise mais aprofundada acerca do país selecionado, a fim de que seja compreendida de forma mais detalhada o comportamento do mercado e dos clientes para confirmação da escolha (Cavusgil et al., 2004).

\subsection{O método de Papadopoulos, Chen e Thomas}

O método sugerido por Papadopoulos, Chen e Thomas (2002), se baseia em dois pilares principais: o potencial da demanda e as barreiras comerciais. Em uma primeira etapa, os autores selecionaram 17 possíveis mercados alvos pertencentes à Organização para a Cooperação e Desenvolvimento Econômico (OCDE), que atualmente é composta por 34 
membros. A justificativa utilizada pelos autores é de que são países que possuem dados atualizados disponíveis e um maior desenvolvimento econômico.

A fim de analisar o grupo "potencial de demanda" para o produto a ser exportado, são sugeridos quatro indicadores. O primeiro deles é denominado "consumo aparente" e visa identificar o tamanho do mercado consumidor para o produto em análise. 0 segundo indicador utilizado para calcular o potencial de demanda é a penetração da importação, retratado através da porcentagem que as importações representam frente ao consumo aparente. $O$ terceiro indicador é a "vantagem de origem", que identifica a participação do país de origem nas importações do mercado alvo. O último indicador que compõe este grupo é a similaridade de mercado, que é um indicador composto por quatro variáveis, sendo estas a expectativa de vida, o PIB/Capita, a produção de energia e a participação das importações frente ao PIB.

O segundo grupo evidenciado pelo método é o das barreiras comerciais, construído através de quatro indicadores. O primeiro indicador mede as barreiras tarifárias e é obtido através de uma média ponderada da tarifa aplicada nos últimos anos. O segundo mede as barreiras não tarifárias a partir da base de dados fornecida pela Organização Mundial do Comércio, através da qual foram observadas a aplicação de 20 diferentes barreiras não tarifárias aos países analisados. O terceiro indicador é a distância física entre os países. O último indicador é a variação da taxa de câmbio entre os países em relação ao ano anterior.

Com a finalidade de escalonar os indicadores e possibilitar uma comparação entre eles, Papadopoulos et al. (2002) utilizaram um processo proposto por Liander (1967). Para cada indicador, o menor valor identificado para um país é subtraído do maior valor de outro país para o mesmo indicador. Essa diferença é dividida por dez, formando dez intervalos de valores, que são classificados de 1 (um) a 10 (dez), do menor valor para o maior valor. Dessa forma, os países são inseridos dentro destes intervalos, recebendo a respectiva pontuação do grupo.

Papadopoulos et al. (2002) ressaltam que a estratégia mais ou menos ofensiva adotada pela empresa afeta a seleção do mercado alvo e, portanto, eles propõem utilizar ponderações diferentes para os indicadores e grupos, de acordo com a estratégia da empresa. Ao serem aplicadas ponderações aos valores identificados para cada indicador de acordo com a faixa de valor em que se inserem, cada país terá uma pontuação de 1 a 10 para o grupo de "Potencial de Demanda" e para o grupo de "Barreiras Comerciais". Em seguida, aplica-se, de acordo com a estratégia adotada pela empresa, a ponderação por grupo, chegando-se a um valor final por país.

A partir desta pontuação final, os países são divididos em quatro grandes conjuntos: (a) os que possuem um valor acima de seis, considerados países com grande oportunidade, (b) países com pontuação entre quatro e seis, considerados países de alta/média oportunidade, (c) países com pontuação entre três e quatro, considerados países com média/baixa oportunidade, e (d) países com pontuação inferior a três, considerados países com baixa oportunidade. Dessa forma, os tomadores de decisão irão ter como opções de mercado para exportar, um ou mais países que pertencerem aos grupos com pontuação acima de seis.

6.4 Método do Centro Internacional de Negócios do Rio Grande do Sul

O Centro Internacional de Negócios do Rio Grande do Sul (CIN-RS), através de sua área de Inteligência Comercial, realiza estudos personalizados de seleção de mercado a fim de auxiliar as empresas na identificação de mercados para exportar. Em um primeiro momento é realizado um diagnóstico de questões internas à empresa. São observados fatores próprios da instituição, a exemplo de porte da empresa, maturidade, características do tomador de decisão, estratégia da empresa e questões tecnológicas, a fim de vislumbrar o cenário interno da firma e, dessa forma, identificar as suas necessidades.

Uma vez compreendido o perfil da empresa e os benefícios almejados no comércio exterior, a próxima etapa é a definição de um grupo inicial de países a serem analisados. Para alcançar esta listagem de países, são realizadas principalmente análises setoriais sobre o produto a ser exportado, que são apresentadas aos tomadores de decisão a fim de realizar, em conjunto com eles, este primeiro filtro. Nesta etapa, os tomadores de decisão têm um papel importante, não somente nas escolhas durante processo decisório de seleção de mercados, mas também na proposição de sugestões de países sobre os quais eles possuem maior interesse. Na maior parte dos casos, esta seleção é feita por região 
geográfica, procurando-se identificar, por exemplo, regiões ou continentes a serem explorados. Existe, no entanto, a possibilidade de utilização de outros critérios para realizar esta seleção inicial.

Em um segundo momento são coletados dados referentes aos países selecionados. Os indicadores utilizados por este método são bastante variados, sendo identificados de acordo com as necessidades do produto a ser exportado. São utilizados indicadores quantitativos relacionados com aspectos macroeconômicos, demográficos, comerciais, entre outros, que permitam uma visão abrangente e comparativa dos países.

Com a análise destes indicadores, as opções de potenciais mercados são reduzidas para um número de aproximadamente três países. Neste momento, o método sugere uma avaliação qualitativa. São analisadas caraterísticas microeconômicas como as principais empresas importadoras, as mais importantes origens de suas importações, a participação brasileira nas importações das empresas, entre outros. Após é feita a escolha por um mercado alvo, para o qual é realizada uma análise das oportunidades internas para o produto específico.

O método apresenta um cronograma que estimula uma participação ativa e constante dos tomadores de decisão da empresa. Esta participação e a realização de etapas decisórias intermediárias visam garantir que a seleção do mercado para exportação esteja alinhada com a visão institucional, visto que, mesmo em situações iguais, empresas que exportam o mesmo produto podem ter preferencias diferentes por mercados alvos.

\section{Similaridades e diferenças entre os métodos}

Quatro dimensões foram identificadas como essenciais em um processo de seleção de mercado para exportação: distância psíquica, análise setorial, etapas da seleção e indicadores. A análise comparativa dos métodos é realizada a seguir de acordo com estas dimensões.

\subsection{Distância psíquica}

A distância psíquica é muito destacada pela vertente comportamental e mostra-se bastante importante principalmente para empresas de pequeno e médio porte, que não possuem uma cultura exportadora (Hollensen, 2011). Este conceito, no entanto, não foi muito aprofundado pelos quatro métodos observados. Existe uma tendência empírica de, nos casos de exportações proativas e planejadas, as empresas iniciarem seu processo de exportação por países com os quais possuem uma maior 'identificação', devido à segurança que isso acarreta aos tomadores de decisão. Além disto, soma-se o fato de existir uma maior probabilidade da ocorrência de acordos comerciais com países considerados mais próximos, o que pode resultar em uma grande vantagem competitiva em relação aos demais concorrentes internacionais

O método utilizado pela APEX incorpora esta visão dentro da sua etapa inicial, quando inclui na préseleção dos 60 maiores importadores mundiais, os países da mesma região que estiverem entre os 100 maiores importadores. Não é realizada, no entanto, uma análise mais aprofundada e o conceito acaba estando mais relacionado à proximidade física - que possui, de fato, uma influência direta e importante na distância psíquica (Johanson \& Vahlne, 2009).

O segundo método apresentado utiliza a técnica de agrupamento, que permite esse reconhecimento de países que possuem maior similaridade. Os indicadores utilizados representam fatores econômicos, populacionais e de desenvolvimento. Não são incluídos na análise os dados do país exportador, fazendo com que não seja observada a distância psíquica entre o país de destino e de origem.

O método desenvolvido por Papadopoulos et al. (2002) é o que mais atenta para o conceito de distância psíquica, que é inserido através do indicador "Similaridade de Mercado". Este indicador é composto por quatro variáveis que medem a similaridade entre o mercado exportador e os mercados alvos em quatro diferentes dimensões. No entanto, percebe-se que esta aplicação é realizada apenas após a etapa inicial de seleção dos 17 mercados pertencentes à $O C D E$, e, dessa forma, ela perde a sua potencialidade pois o corte inicial restringe a um grupo bastante específico as opções de mercado.

No método utilizado pelo CIN-RS a distância psíquica não é investigada através de indicadores. No entanto, na etapa inicial de seleção da região a ser analisada, ela possui um peso importante, visto que a tendência é dar uma maior atenção aos países pertencentes à mesma região do país exportador. 


\subsection{Análise setorial}

A análise realizada apenas com fatores macroeconômicos faz com que sempre sejam selecionados países com um maior grau de desenvolvimento que, reforçam os especialistas, tendem a serem mercados mais difíceis para inserção dos produtos. O alto grau de exigência destes mercados, a forte concorrência qualificada e as barreiras técnicas exigem um produto inovador e uma exportação muito bem estruturada. Estes mercados não costumam ser o mercado alvo ideal para empresas novatas dentro do comércio internacional. Ao serem analisados apenas os fatores macroeconômicos, existe uma alta probabilidade de que sejam retirados da análise países que apresentam grandes oportunidades para o produto específico a ser exportado.

O método desenvolvido pela APEX atenta para a análise do mercado alvo do setor especifico para o qual o estudo se aplica. Observa-se que, além do tema "Setorial", que incluí unicamente variáveis específicas sobre o mercado do produto analisado, os temas de "Comércio" e "Concorrência" também utilizam variáveis que recortam um cenário mais restrito do produto.

O método apresentado por Cavusgil et al. (2004), por outro lado, não inclui esta visão dentro de seu estudo, relacionando apenas variáveis que representam um nível mais macro das dimensões dos países analisados. No terceiro método existe uma maior preocupação em relação ao mercado setorial, o que pode ser identificado nos dois grupos observados. No grupo "potencial de demanda", a visão setorial está inserida nos indicadores "consumo aparente", "penetração da importação" e "vantagem de origem", e no grupo "barreiras comerciais" ela é analisada nos indicadores "barreiras tarifárias" e "barreiras não tarifárias". Esta preocupação em uma análise mais setorial também é observada no método utilizado pelo CIN, que direciona e adequa seus indicadores para esta visão de produto durante toda a análise.

\subsection{Etapas da seleção}

Percebe-se que existe uma diferença importante entre os métodos na forma através da qual eles organizam a análise das informações e entre as etapas propostas para identificação dos potenciais mercados. A primeira etapa, de afunilamento das opções de mercado a serem analisados, é um ponto delicado dos métodos, uma vez que eles precisam garantir que o número de países remanescentes para a segunda fase de análise de variáveis não seja muito grande a ponto de inviabilizar a obtenção dos dados, e nem tão pequeno a ponto de excluir oportunidades.

O método da APEX restringe o número inicial de países através do valor de importação que estes países possuem para o produto em análise, reduzindo a um número de aproximadamente 60 possíveis mercados. Em seguida, eles combinam esta variável com o dinamismo dos países, fazendo com que as combinações com maior potencial passem para a segunda parte de análise de 35 indicadores.

O método de agrupamento e classificação não aplica uma restrição inicial, fazendo com que seja necessário obter para todos os mercados possíveis as informações das 29 variáveis sugeridas. Isto pode ser particularmente difícil de aplicar em empresas que possuem uma pequena equipe ou recursos escassos.

O terceiro método, desenvolvido por Papadopoulos et al. (2002), realiza o oposto do método de agrupamento e classificação, visto que restringe já no primeiro momento a análise a um número de 17 países. Essa técnica tem como fragilidade a possível exclusão de potenciais mercados que, por não pertencerem à OCDE, não teriam seus dados coletados para análise.

O método utilizado pelo CIN também realiza um corte inicial mais abrupto, mas que, diferentemente de Papadopoulos et al. (2002), é feito em conjunto com o tomador de decisão, baseado em uma avaliação do cenário externo e das indicações específicas deste tomador de decisão. Observa-se que a seleção inicial sofre uma maior influência das percepções gerais de cenário, da equipe e da empresa, e não de dados puramente econômicos, como proposto pelo terceiro método apresentado.

Na etapa de análise dos indicadores para os países previamente selecionados, é verificada uma maior similaridade entre os métodos. O método da APEX, de Papadopoulos, Chen e Thomas e do CIN-RS tornam os países comparáveis entre si para cada indicador. O primeiro método aplica quatro diferentes pontuações de acordo com o seu desvio padrão em relação à média do indicador, enquanto que o segundo propõe a criação de dez diferentes faixas de valor, nas quais os países são inseridos. 0 método do CIN-RS não realiza agrupamento dos países em faixas ou pontuações unificadas, mas 
consegue classificá-los em ordem de pontuação, permitindo a comparação.

Esta técnica também é observada no método da Michigan University, na etapa de rankeamento. Destaca-se, no entanto, que, a classificação sugerida por este último método, baseia-se no Índice Potencial de Mercado, que analisa 89 países e fornece um resultado final único, que não permite com que sejam incluídos ou retirados indicadores considerados pertinentes ou não necessários.

Após a etapa de análise quantitativa dos indicadores, observada nos quatro métodos, três deles identificam a necessidade de uma visão qualitativa dos países selecionados. A exceção é o método de Papadopoulos et al. (2002). A importância da etapa qualitativa da análise foi destacada pelos três especialistas entrevistados, visto que permite compreender particularidades e restrições que não são possíveis de serem captadas apenas através de indicadores. É a oportunidade de incluir uma visão mais subjetiva e o conhecimento empírico dos próprios tomadores de decisão, adquiridos através de experiências anteriores, participação em feiras e contatos pessoais.

\subsection{Indicadores}

Nos quatro métodos analisados, as informações quantitativas são obtidas através de dados estruturados. Os indicadores selecionados, no entanto, são bastante variáveis e apontam para os diferentes focos.

O método da APEX e do CIN-RS utilizam indicadores que mostram uma atenção ao cenário setorial, buscando a inserção de dados de comércio e concorrência específicos para o produto analisado. Destaca-se nestes dois métodos, a utilização de indicadores que buscam fornecer uma imagem não apenas estática da situação atual, mas também da evolução desta nos últimos anos, apontando para possíveis tendências. O CIN-RS destaca-se ainda pela percepção da cadeia de valor do produto, procurando analisar indicadores que observam, além do produto a ser exportado, outros produtos a ele diretamente relacionados.

O método de agrupamento e classificação insere uma variável demográfica aos indicadores, não analisada nos outros métodos. Ele também introduz indicadores de cunho social, a exemplo da expectativa de vida, taxa de alfabetização e gastos públicos em educação, que podem fornecer uma informação mais completa do que o indicador usualmente utilizado de PIB per capita. Destacam-se também os indicadores que avaliam as condições de infraestrutura dos países, visão também não incluída nos outros métodos.

Os indicadores utilizados no método apresentado por Papadopoulos et al. (2002) diferenciam-se dos utilizados nos outros métodos principalmente pelo foco que é dado nas barreiras comerciais. Os indicadores que compõem o grupo de "potencial de demanda" são similares aos utilizados pela APEX, mas o grupo "barreiras comerciais" destaca-se principalmente pela utilização dos indicadores que identificam a existência de barreiras não comerciais e a variação da taxa de câmbio, não analisados nos outros métodos. Os três especialistas entrevistados consideraram primordial a atenção às barreiras comerciais, sejam elas tarifárias e não tarifárias. As normas exigidas podem barrar a importação de um produto ou exigir mudanças em sua concepção e, dessa forma precisam ser consideradas na análise.

Uma semelhança entre todos os métodos é a utilização de indicadores principalmente econômicos, que fornecem um cenário da saúde financeira e comercial do país. Aponta-se para a falta de indicadores que forneçam uma melhor compreensão da dimensão política destes países, o que poderia ser explicado por uma maior dificuldade de transpor estas informações em dados estruturados e comparáveis.

É preciso destacar a grande quantidade de dados que alguns destes métodos exigem. Percebe-se que poderia haver uma redução do número de indicadores quantitativos, através da seleção de alguns mais expressivos, tais como participação do país de origem nas importações do mercado alvo analisado, valor do frete por unidade e evolução da taxa de câmbio. Isto permitiria uma análise quantitativa mais rápida e eficaz, direcionando os recursos da empresa para a etapa de análise qualitativa e compreensão dos mercados alvos.

Os métodos procuram inserir a visão deste cenário externo dentro da análise através de dados estruturados e, em sua maioria, estáticos. A análise é realizada, na maior parte dos métodos apresentados, através de comparações numéricas, o que representa uma forma prática e que pode ser generalizada, absorvida e aplicada pelo responsável por esta análise dentro das empresas. No entanto, percebe-se 
que elas não fornecem um direcionamento na interpretação mais aprofundada destas informações, uma orientação mais detalhada para a fase de análise qualitativa.

Vê-se, portanto, que os três primeiros métodos analisados se direcionam, no clássico dilema entre detalhamento mais alto versus custos e tempo de análise, para uma opção mais rápida e acessível que, consequentemente, fornece um cenário menos minucioso. O método aplicado pelo CIN-RS, no entanto, fornece um estudo mais detalhado e que exige um maior envolvimento e tempo para análise dos mercados. Todavia, esta última opção muitas vezes não é acessível para empresas de pequeno e médio porte, que necessitam utilizar os seus recursos internos para realizar esta análise e que, dessa forma, não tem acesso a informações privilegiadas e pagas.

\section{Considerações finais}

Na identificação dos mercados alvos para exportação, a compreensão das informações externas é bastante complexa, pois envolvem um ambiente menos conhecido aos tomadores de decisão. Os métodos de seleção de mercado procuram dar um direcionamento às empresas de como obterem e interpretarem informações que possam fornecer um maior conhecimento sobre as possibilidades de mercado alvo.

O presente estudo comparou quatro diferentes métodos de seleção de mercado para exportação, para os quais foram observadas as diferentes formas através das quais os dados são transformados em conhecimento. Observa-se que, embora sejam mais acessíveis, estes métodos dificilmente são aplicáveis para a realidade das pequenas e médias empresa, que normalmente não possuem um setor especializado para realizar este tipo de trabalho. Estes métodos exigem uma grande quantidade de informações e tempo dedicado para análise de dados.

Em termos acadêmicos, o presente estudo contribui ao fornecer uma visão comparativa referente a quatro diferentes métodos de seleção de mercado para exportação, possibilitando identificar pontos críticos dos métodos e questões consideradas relevantes por todos eles. Ele também fornece uma visão sobre os pontos onde ocorrem divergências, permitindo uma discussão sobre quais as alternativas mais adequadas a serem implantadas em cada situação.

Em relação às suas implicações gerenciais, este estudo possibilita que, sobretudo empresas de pequeno e médio porte, possam adquirir maior conhecimento sobre os métodos existentes de seleção de mercado. Ao analisarem os métodos investigados, os tomadores de decisão e as equipes direcionadas a esta função poderão identificar qual o método mais adequado à conjuntura de sua organização. Além disto, o estudo fornece um direcionamento em relação a variáveis e pontos considerados importantes a serem analisados durante um estudo de mercados potenciais, mesmo quando optado pela não utilização de um método estruturado. As empresas podem utilizar os resultados deste estudo como uma orientação para a formulação de seus planos de exportação visando a redução dos riscos associados à atividade de exportação.

Este estudo teve como importante limitação a dificuldade de acesso a métodos de seleção de mercados para exportação. Além de serem escassos os estudos estruturados referentes a este tema, aqueles existentes, muitas vezes, não disponibilizam as informações completas de sua aplicação, visto que são considerados conhecimentos que garantem uma vantagem competitiva aos seus detentores.

Destaca-se que uma futura continuação deste estudo é o de, a partir da análise destes métodos e de outros métodos de seleção de mercado para exportação, realizar-se a proposição de um novo método, mais simplificado e que possa ser empregado pelas próprias empresas exportadoras.

\section{Referências}

- Andersson, S. (2000). The internationalization of the firm from an entrepreneurial perspective. International Studies of Management and Organization, 30(1), 6392.

- APEX (2015). AgÊNCIA BRASILEIRA DE PROMOÇÃO DE EXPORTAÇÃO E INVESTIMENTOS, 2015. Recuperado em 23 abril 2015, de http://www.apexbrasil.com.br/projetos-setoriais-comentidades-parceiras.

- Barreto, A. A. (2012). A questão da Informação. In: Starec, Claudio (Org). Gestão da Informação, Inovação e Inteligência Competitiva: como transformar a informação em vantagem competitiva nas organizações (pp. 3-14). São Paulo: Saraiva. 
- Bose, R. (2008). Competitive intelligence process and tools for intelligence analysis. Industrial Management and Data Systems, 108(4), 510-528.

- Buzzerio, F. G., \& Marcondes, R. C. (2014). A Inteligência Competitiva na Perspectiva de ser uma Fonte de Vantagem Competitiva e suas Contribuições Estratégicas. Revista de Ciências da Administração, 16(40), 235-249.

- Calof, J. L., \& Wright, S. (2008). Competitive intelligence: A practitioner, academic and interdisciplinary perspective. European Journal of Marketing, 42(7/8), 717-730.

- Carneiro, J. M. T., \& Dib, L. A. (2008). Avaliação comparativa do escopo descritivo e explanatório dos principais modelos de internacionalização de empresas. Internext - Revista Eletrônica de Negócios Internacionais da ESPM, 2(1), 1-25.

- Cavusgil, S. T., Kiyak, T., \& Yeniyurt, S. (2004). Complementary approaches to preliminary foreign market opportunity assessment: Country clustering and country ranking. Industrial Marketing Management, 33(7), 607-617.

- Coelho Neto, J. E. M. (2013). Estratégia de internacionalização da Grande Porto: seleção, modos de entrada e marketing-mix na abordagem dos mercados internacionais. Dissertação de Mestrado, Instituto Politécnico do Porto. Instituto Superior de Contabilidade e Administração do Porto), Porto, Portugal.

- Dal-Soto, F., Alves, J. N., \& Bulé, A. E. (2014). Análise do Processo de Internacionalização do Modelo de Uppsala: caminhos para as empresas Brasileiras. Estudo \& Debate, 21(1).

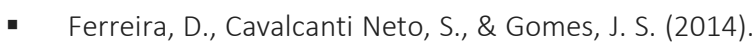
Internacionalização de empresas: uma análise bibliométrica da produção científica dos últimos cinco anos. Revista Magistro, 1(9).

- Hollensen, S. (2011). Global Marketing: A decision oriented approach (5 $5^{\text {th }}$ ed.). England: Pearson Education Limited.

- Fuld, L. M. (2007). Inteligência competitiva: como se manter à frente dos movimentos da concorrência e do mercado. São Paulo: Elsevier.

- Johanson, J., \& Mattsson, L. G. (1988). Internationalization in industrial systems: a network approach. In: Hood, H. \& Vahlne, J. (Eds.). Strategies in foreign competition. London: Croom Helm.

- Johanson, J., \& Vahlne, J. E. (1977). The internationalization process of the firm - a model of knowledge development and increasing foreign market commitments. Journal of international business studies, 8(1), 23-32.

- Johanson, J., \& Vahlne, J. E. (2009). The Uppsala internationalization process model revisited: From liability of foreignness to liability of outsidership. Journal of International Business Studies, 40(9), 14111431.

- Kovacs, E. P., de Moraes, W. F. A., \& de Oliveira, B. R. B. (2007). Redefinindo conceitos: um ensaio teórico sobre os conceitos-chave das teorias de internacionalização. REGE Revista de Gestão, 14, 17-29.

- Kontinen, T., \& Ojala, A. (2010). Internationalization pathways of family SMEs: Psychic distance as a focal point.Journal of Small Business and Enterprise Development, 17(3), 437-454.

- Liander, B., Terpstra, V., Yoshino, M. Y., \& Sherbini, A. A. (1967). Comparative analysis for international marketing. Boston: Allyn and Bacon.

- Miller, J. (2002). O milênio da inteligência competitiva. Porto Alegre: Bookman.

- Oviatt, B. M., \& McDougall, P. P. (1994). Toward a theory of international new ventures. Journal of international business studies, 25(1), 45-64.

- Papadopoulos, N., Chen, H., \& Thomas, D. R. (2002). Toward a tradeoff model for international market selection. International Business Review, 11(2), 165192.

- Prodanov, C. C., de Freitas, E. C. (2013). Metodologia do Trabalho Científico: Métodos e Técnicas da Pesquisa e do Trabalho Acadêmico. Novo Hamburgo: Editora Feevale.

- Sharp, S. (2009). Competitive intelligence advantage. Hoboken: Wiley.

- Teixeira, A. P. P., \& Flores, F. S. (2014). O Modelo de Internacionalização de Upssala sob a ótica da visão baseada em recursos (RBV). REAVI-Revista Eletrônica do Alto Vale do Itajaí, 3(3), 01-12.

- Viana, C., \& Hortinha, J. M. R. (2009). Marketing internacional. Edições Sílabo.

- Woida, L. M., \& Valentim, M. L. P. (2013). Cultura informacional voltada ao processo de inteligência competitiva organizacional: a relação entre as pessoas, a informação, e as tecnologias de informação e comunicação. In: VII ENANCIB - Encontro Nacional de Pesquisa em Ciência da Informação, Marília. Anais. 


\section{APÊNDICE 1}

Roteiro de perguntas utilizado nas entrevistas com os especialistas.

1. Qual a sua visão sobre a utilização de métodos para seleção de mercados para exportação?

2. Na prática, as empresas utilizam métodos? Elas teriam maiores ganhos se utilizassem? Quais os principais ganhos?

3. Como deveriam ser inseridas a visão qualitativa e quantitativa dentro da análise?

4. Qual a sua visão sobre a utilização de indicadores? Em caso de trazerem benefícios, quais os principais indicadores que poderiam auxiliar na visualização de cenários?

5. Entre os métodos apresentados, quais as principais similaridades que identificas?

6. Quais os pontos fortes e pontos fracos de cada método?

7. Quais etapas eliminarias ou acrescentarias nas análises?

8. O que consideras mais importante na seleção de um mercado para exportação?

\section{Sobre as autoras}

- Moema Pereira Nunes é Doutora em Administração. Professora da Faculdade de Administração, Contabilidade e Economia - FACE e da Pontifícia Universidade Católica do Rio Grande do Sul - PUC/RS, Porto Alegre/RS, Brasil.E-mail: moemanunes@hotmail.com

- Laura de Souza Lequain é especialista em Inteligência Competitiva pela Pontifícia Universidade Católica do Rio Grande do Sul-PUC/RS, Porto Alegre/RS, Brasil.E-mail: lauralequain@falconi.com 


\section{The application of \\ competitive intelligence in export markets selection: A comparative analysis of four methods}

Moema Pereira Nunes and Laura de Souza Lequain

Pontifical University Catholic of Rio Grande do Sul - PUC/RS, Porto Alegre, RS, Brazil

\section{ARTICLE DETAILS}

Article history:

Received 21 December 2015

Accepted 10 November 2016

Available online in 30 December 2016

Double Blind Review System

Scientific Editor

Ilan Avrichir

\section{Keywords:}

Competitive Intelligence

Export

Market selection.

\begin{abstract}
The insertion in the international market through exports is an important step in the growth of an organization. It is a major challenge for decision makers in small and medium-sized enterprises. This paper analysis as Competitive Intelligence assists this choice through four methods of selecting export markets. Using primary and secondary data, four methods were investigated. Four strategic dimensions were identified for the development of market selection for export: psychic distance, sector analysis, steps of selection and indicators. The similarities and differences between these methods from the analysis of these dimensions were identified. Among the results, it was verified the wide range of indicators used, the attention given to the psychic distance and the importance of sector analysis.
\end{abstract}

(C) 2016 Internext | ESPM. All rights reserved!

Para citar este artigo:

Nunes, M. P. \& Lequain, L. S. (2016). A utilização da inteligência competitiva na seleção de mercados para exportação: Uma análise comparativa de quatro métodos. Internext - Revista Eletrônica de Negócios Internacionais, 11 (3), 22-35. DOI: 10.18568/1980-4865.11322-35

Para acessar este artigo: $h t t p: / / d x . d o i . o r g / 10.18568 / 1980-4865.11322-35$ 